\title{
Research on Quality Control in Professional Practice Link of Full-time Master of Agriculture
}

--- A Case Study of Hunan University of Humanities, Science and Technology

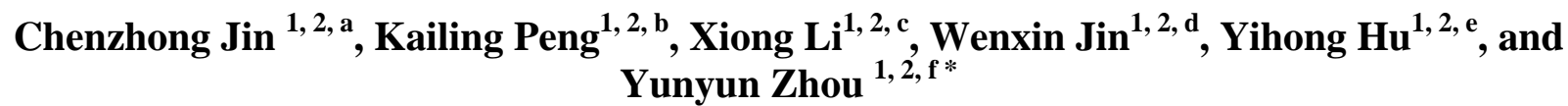

${ }^{1}$ Hunan Provincial Collaborative Innovation Center for Field Weeds Control, Loudi, Hunan, China

${ }^{2}$ Key Laboratory of Harmless Application of Pesticide in Hunan Higher Education, Hunan University of Humanities, Science and Technology, Loudi, Hunan, China

aemail: 532479626@qq.com, bemail: asdw73@qq.com, email: 251925070@qq.com, demail: superjwx@qq.com, ${ }^{\mathrm{e} e m a i l: ~ h u y h o n g w a n g y i @ 163 . c o m, ~}{ }^{\mathrm{f}} \mathrm{email:}$ 67547204@qq.com

*Corresponding author

Keywords: master of agriculture, practice link, quality control

Abstract: The development of professional degree at home and abroad is introduced. The investigation and study on methods for quality control in professional practice link are conducted during the cultivation of full-time agricultural professional degree postgraduates in Hunan University of Humanities, Science and Technology, which provides ideas and methods for cultivating professional degree postgraduates.

\section{Introduction}

With mature and perfect running mechanism, the education of professional degree postgraduates in western developed countries is good, and a large number of talents have been cultivated for all walks of life. The cultivating mode for professional degree postgraduates in America is the most advanced in the world, and the cultivation of professional degree postgraduates has dominated the postgraduates education in America recently ${ }^{[1]}$. The education of professional degree postgraduates in America is guided by students needs and market requirements, and led by practice. Such cultivation mode for talents with professionalization, specialization and diversification provides good reference to the education development of professional degree postgraduates in the rest of the world ${ }^{[2]}$. The education of professional degree postgraduates in Japan starts later than our country, and its blueprint is derived from America. The Japanese government has encouraged the development of professional degree postgraduates education recently, so it has had a systematic and rapid development since the beginning of this century ${ }^{[3]}$.

Since 2005, the research on education of full-time professional degree postgraduates has become hot domestically, and many scholars have focused their study on its cultivation mode, curriculum system, teaching mode, teaching practice ability, quality evaluation system for postgraduate's dissertation and quality assurance system for training postgraduates; however, there have been fewer studies on professional practice link of full-time professional degree postgraduates in agriculture $^{[4-9]}$. Here, the scarce studies on some procedures during the cultivation of full-time professional degree postgraduates in agriculture are added, which provides certain basic researches for the fundamental establishment of an effective and scientific quality assurance system in professional practice link of full-time professional degree postgraduates and the education reform of full-time professional degree postgraduates in agriculture.

The agricultural professional degree postgraduates of Hunan University of Humanities, Science and Technology, intramural and extramural academic advisors are taken as research objects, and a scientific and effective quality assurance system in professional practice link of full-time professional degree postgraduates is explored and established, which provides certain theoretical 
basis for the perfection of postgraduates management and the improvement of cultivation quality of full-time professional degree postgraduates education.

\section{Purpose and significance of Professional Practice of Agricultural Professional Degree Postgraduates}

According to the cultivating target of agricultural professional degree postgraduates, it is characterized by applicability. Professional practice link is the best way to embody the "applicability", so the cultivation in professional practice link plays a crucial role in the cultivating quality of postgraduates. However, most of the full-time agricultural professional postgraduates are from fresh graduates, including transdisciplinary students, and they don't have so much experience of professional academic researches related with agriculture and professional practice of agricultural technology extension except graduation practice in their junior colleges and undergraduate universities, which lead it difficult to achieve the cultivating target. Professional practice link is the key part of cultivating application-oriented, innovative and versatile talents, and if there are problems in practice link, the cultivation quality of professional degree postgraduates will be influenced to a great extent. When it comes to the education of full-time agricultural professional degree postgraduates, the content of professional practice is the basis for its success. In addition, scientific and effective quality control in professional practice link is crucial to guarantee its quality.

\section{Investigation and Research on the Quality of Professional Practice of Postgraduates}

The curriculum system, the management and evaluation of professional practice process for postgraduates are involved in this paper. It aims to find out the factors that influence the quality of professional practice, improve the existing problems and puts forward some feasible solutions; thus a scientific and effective quality assurance system in professional practice link of full-time professional degree postgraduates is explored and established, which provides certain theoretical basis for the perfection of postgraduates management and the improvement of cultivation quality of full-time professional degree postgraduates education.

\section{Contents of Investigation and Research}

\subsection{Relevance between the curriculum system and the professional practice of full-time} agricultural professional degree postgraduates

Investigate whether the professional practice is closely related with curriculum knowledge, and the curriculum knowledge can be fully applied to professional practice. Analyze whether the curriculum system settings adapt to the present cultivation of professional practice ability for agricultural professional degree postgraduates. Provide guidance to appropriately set the curriculum system according to the investigation and analysis on the system of knowledge and abilities required by professional practice.

\subsection{Investigation on the current status of profession practice link of full-time agricultural professional degree postgraduates}

Prepare for professional practice. Investigate the necessity of professional practice, and conduct the understanding and positioning of professional practice units. Know about the management system in professional practice units for the professional practice of postgraduates and investigate whether its post settings are in accordance with the cultivation target.

Investigations on the current situation of professional practice include the learning and working status of postgraduates, the supervising degree of instructors and the work of university administrative department. Investigations on weekly and monthly reports, practice records, practice schedule and time are conducted. The guidance and attentiveness that postgraduates received from the practice instructor, intramural and extramural academic advisors during the process of 
professional practice are also investigated. Besides, researches are performed on methods of the visit to practice bases related with every cultivating field, methods of visitation by random inspection of the administrative department of postgraduates, and the correlation between the system of rewards and penalties and the professional practice of postgraduates.

Make a work summary after professional practice. The evaluation work of professional practice made by the administrative department and professional practice units involves in evaluating the whole practice process and achievements gained by postgraduates during the professional practice. Summarize the evaluation work of professional practice units, intramural and extramural academic advisors, the professional practice instructors and the administrative department made by postgraduates.

\subsection{Problems caused in the cultivating process of professional practice of full-time agricultural professional degree postgraduates at present}

Based on results of investigation on the status of professional practice link, problems existing in the profession practice link are analyzed.

\subsection{Suggestions for the cultivation of professional practice of full-time agricultural professional degree postgraduates at present}

According to the problems existing in the professional practice link, strategies and suggestions are proposed to improve the quality in professional practice link of postgraduates.

\subsection{Exploration of the system of process management, evaluation index and quality evaluation} of professional practice cultivation for full-time postgraduates in agriculture

On the basis of research results of this project, establish a scientific, suitable and efficient system of process management, evaluation index and quality evaluation of professional practice for full-time agricultural professional degree postgraduates, so as to guarantee the cultivation quality in professional practice link.

\section{Implementations for Investigations and Researches}

1) Interview, questionnaire survey and on-site investigation on the practice base are adopted to check out whether the knowledge of curriculum system is fully applied to the process of professional practice by postgraduates, ascertain the knowledge and abilities required by professional practice and deeply understand the problems existing in the process of professional practice.

2) Make comparative investigation and research on the status of professional practice of postgraduates in other similar universities to integrally grasp the strengths and weaknesses in the professional practice link of agricultural professional degree postgraduates in our university.

3) Tracking studies on professional practice of full-time agricultural professional degree postgraduates are made by interview and questionnaire survey. For example, conduct dynamic tracking studies on postgraduates, instructors and the administrative department of postgraduates.

4) Collect and comprehensively analyze the data from investigations and researches; adjust, improve and optimize the quality guarantee system of professional practice to actually cultivate the professional practice abilities and promote the cultivation quality of full-time agricultural professional degree postgraduates.

\section{Summary}

Many problems are found out according to our investigations and studies. Firstly, there is not enough correlation between some curriculum settings in the curriculum system and the cultivation of practical abilities, so some curriculums need to be reset. Secondly, the intramural academic advisors have failed to give adequate guidance to the practice of postgraduates, especially the off-campus practice. Because of the lack of interaction between postgraduates and their advisors, 
further analysis on practical questions is not performed. Hence, they rely solely on their own experience to solve all problems but not actively seek for scientific problem-solving methods, and that is to say, the problem-solving methods by applying theoretical knowledge to improve and correct the mistakes is not adopted. Generally speaking, during the practice link of cultivation of postgraduates in professional degree with the same type, the intramural academic advisors provide fully guidance to the off-campus practice of postgraduates, so a consensus on off-campus practice goals for postgraduates is reached between intramural and extramural academic advisors. Thirdly, the extramural academic advisors can not accurately grasp the connotation of cultivation of professional degree postgraduates in our university.

There are many distinctive advantages in the practice link of cultivation for agricultural professional degree postgraduates in our university. Firstly, off-campus practice is dominated by enterprises, application-oriented academy of agricultural sciences and other scientific research institutions. During the professional practice, not only are the practical abilities cultivated to help postgraduates solve problems in the production and management process of the enterprise, but also are the latest applied and leading-edge scientific technological achievements mastered and is the industry development trend grasped by the postgraduates to provide guidance to their employment. In addition, a set of management system from the administrative department of postgraduates can effectively supervise the whole process of practice, which plays a crucial role in enhancing the cultivation quality of postgraduates. Next, the survey data will be summarized and analyzed to provide advice and guidance to quality control in the practice link of postgraduates.

\section{Acknowledgement}

This research was financially supported by the Innovation Base for Postgraduates Cultivation of Hunan Province (2261602), the Research Project of Teaching Reform of Degree and Graduate Education in Hunan (JG2016B106) and the Open Fund for Innovation Platform of Universities in Hunan Province (16K047,15K066).

\section{References}

[1] Q. Wang. (2005) Comparison and enlightenment of the four foreign postgraduate education modes. University Education Science, 1, 82-85.

[2] L. Shi. (2010) Comparison and discussion of domestic and foreign cultivation mode for postgraduates. Journal of Southeast University, 2, 117-121.

[3] Y. Zhu. (2011) Thinking on the education of agricultural professional degree postgraduates in China and foreign Countries. Agricultural Education Research, 4, 8-10.

[4] B. Huang. (2010) new era for the development of professional degree graduate education. Academic Degrees and Graduate Education, 10, 1-7.

[5] G. Wen, W. Jiang, H. Chen. (2010) make all efforts to ensure the cultivation quality of full-time professional degree postgraduates. Academic Degrees \& Graduate Education, 8, 1-4.

[6] J, Li, Y. Zhao. (2012) Discussion on the status of professional practice in the system of professional degree postgraduates cultivation. Journal of Liaocheng University, 4, 104-106.

[7] W. Jin, S.Li,X. Li. (2017) Practice for Cultivating Top-level Postgraduates of Agriculture Relied on Collaborative Innovation Platform. Advances in Social Science Education and Humanities Research, 1, 185-187.

[8] J. He, J. Wang, B. Ou. (2009) Investigation and analysis on the cultivation of master of agricultural extension. China Agricultural Education, 4, 16-20.

[9] D. Yue, Y. Huang. (2009) Problems and countermeasures concerning the cultivation of master of agricultural extension. Journal of Hebei Agricultural University: Agriculture and Forestry Education Edition, 3, 270-272. 